\title{
Inter-trial effect in luminance processing revealed by magnetoencephalography*
}

\author{
Efecto inter-ensayo en el procesamiento de iluminación \\ revelado por magnetoencefalografía
}

Recibido: junio 1 de 2012 | Revisado: agosto 1 de 2012 | Aceptado: agosto 20 de 2012

\author{
AKI KONDO ** \\ KATSUMI WATANABE *** \\ The University of Tokyo, Japan
}

Doi:10.11144/Javeriana.UPSY12-5.itel

Para citar este artículo: Kondo, A., \& Katsumi, W. (2013). Inter-trial effect in luminance processing revealed by MEG. Universitas Psychologica, 12(5), 1559-1565. Doi:10.11144/Javeriana.UPSY12-5.itel

Acknowledgements: This study was supported by the Hokuriku Innovation Cluster for Health Science (MEXT Program for Fostering Regional Innovation, Japan) and the Japan Society for Promotion of Science.

** University of Tokyo. Research Center for Advanced Science and Technology, Correspondance to: Aki Kondo. Research Center for Advanced Science and Technology. University of Tokyo, 4-6-1, Komaba, Meguro-ku, Tokyo, 1538904, Japan. E-mail: kondo@fennel.rcast.u-tokyo.ac.jp. Tel: +81-3-5452-5249. Fax: +81-3-5452-5249.

*** Research Center for Advanced Science and Technology, University of Tokyo

\section{A B S T R ACT}

In this study, we examined whether luminance processing in the human visual system would exhibit any history effect (i.e., inter-trial modulation) in psychophysical and magnetoencephalographic experiments. A disk was presented against a black background at various luminance levels in a randomized order. During the MEG recording, participants were instructed to rate the brightness of the disk (magnitude estimation) and to report it aloud during inter-stimulus interval. The MEG results showed that the neuromagnetic activation around 200-220 ms after the stimulus onset in the left occipitotemporal regions at a given trial was weaker when the disk luminance in the immediately prior trial was higher. An inverse inter-trial effect was also observed in the psychophysical experiment. These findings suggest that the neuromagnetic activity reflects the inter-trial modulation of luminance processing that correlates with the subjective perception of brightness.

Keywords authors

luminance, inter-trial effect, magnetoencephalography (MEG).

Keywords plus

Perception, occipito-temporal region, Cognitive Science.

\section{RESUMEN}

En este estudio, se examinó si el procesamiento de iluminación en el sistema visual humano exhibie algún efecto de historia (es decir, modulación interensayo) en experimentos psicofísicos y de magnetoencefalografía (MEG). Un disco se presentó contra un fondo negro en varios niveles de iluminación en un orden aleatorio. Durante el registro de MEG, los participantes fueron instruidos para clasificar el brillo del disco (estimación de magnitud) y reportarlo durante el intervalo inter-ensayo. Los resultados de MEG mostraron que la activación neuromagnetica alrededor 200-220 ms después de la aparición de estímulo en las regiones occipito-temporal izquierda en un ensayo dade fue más débil cuando la iluminación de disco en el ensayo inmediatamente antes fue mayor. También se observó un efecto inverso inter-ensayo en el experimento psicofísico. Estos hallazgos sugieren que la actividad neuromagnética refleja la modulación inter-ensayo de procesamiento de iluminación que se correlaciona con la percepción subjetiva de brillo.

Palabras clave autores

Iluminación, efecto inter-ensayo, magnetoencefalografía (MEG).

Palabras clave descriptores

Percepción, región occipito-temporal, ciencia cognitiva. 


\section{Introduction}

When people evaluate sequentially presented items, their evaluation is biased by the preceding items and preceding evaluations. For example, Holland \& Lockhead (1968) presented an auditory stimuli and asked participants to report the subjective loudness by assigning the number from 1 (small) to 10 (large) in successive trials. The result showed that the rating in the current trial was systematically affected by the preceding stimulus and evaluations. If the auditory stimulus was large in the 1-back trial, participants rated the "current" auditory stimulus larger than when the 1-back auditory stimulus was small. This phenomenon is known as the sequential effect (Garner, 1953; Holland, \& Lockhead, 1968; Luce \& Green, 1974; Jesteadt et al., 1977; Treisman \& Williams, 1984; DeCarlo \& Cross, 1990; Stewart et al., 2005; Matthews \& Stewart, 2009b). Typically, the evaluations on the current trial are contrasted to the preceding stimuli, as well as assimilated toward the ratings made on the preceding stimuli. The sequential effect has been widely and robustly observed with physical property of sensory stimuli such as loudness, brightness of sensory stimuli, size of visual object (Ward \& Lockhead, 1970; Ward, 1982; Eriksen \& Hake, 1955).

Despite these classic psychophysical studies, little is actually known about the neural correlates of the sequential effects; whether the neural activities to the "current" stimuli are affected by the "preceding" stimuli and evaluations. Regarding the neural activities to the "current" stimuli and their perceived brightness, recent electroencephalography (EEG) and functional magnetic resonance imaging (fMRI) studies with humans reported a close relationship between perceived brightness contrast and responses in the early visual cortex (e.g., Haynes, Lotto, \& Rees, 2004; Osaka \& Yamamoto, 1978; Wicke, Donchin, \& Lindsley, 1964). For example, Wicke et al. (1964) showed that visual evoked potential (VEP) peak latency varies with stimulus luminance and higher luminance yields faster latency. An fMRI study by Haynes, et al. (2004) showed that the blood oxygenation level-dependent (BOLD) signals in the early visual cortex scaled linearly with the magnitude of change in retinal illumination, simultaneously correlating with subjective ratings of perceived brightness.

Recently, we have also investigated the timing and location of cortical activity related to perceived brightness using magnetoencephalography (MEG) and showed that the luminance stimulus evoked neuromagnetic responses in the occipital region approximately $150 \mathrm{~ms}$ after stimulus onset, and these responses were positively correlated with the subjective ratings of perceived brightness as well as the log-scaled stimulus luminance (Kondo et al., 2010). These results indicate that perceived brightness may be encoded in the early visual cortex.

In this study, we examined whether luminance processing in the human visual system would exhibit any history effect (i.e., inter-trial modulation) in psychophysical and magnetoencephalographic experiment. Especially, we focused on the preceding stimuli and tried to examine its effects on the neural activities to the current stimuli and their perceived brightness. If luminance processing in the human visual system would exhibit inter-trial modulation, the neuromagnetic responses to the current stimuli would be different depending on the luminance of the preceding stimuli. In contrast, if there were no inter-trial modulation, neural activities to the current stimuli would depend solely on its luminance. To examine these hypotheses, we recorded visual evoked magnetic responses while participants evaluate luminance stimuli and examined whether the brightness ratings of current trials were biased by that of immediately preceding trials. 


\section{Method}

\section{Participants}

Eight paid Japanese people participated (4 males and 4 females) in the study. All participants had normal or corrected-to-normal visual acuity.

\section{Materials}

Visual stimuli were generated using PsychToobox software (Brainard, 1997; Pelli, 1997) on a Macintosh computer and projected onto a rear screen, located $32 \mathrm{~cm}$ from the participant's eyes by a projector (PG-B10S; SHARP, Osaka, Japan) via a mirror. The stimulus was a centrally placed white disk (with a diameter of 10 degrees) against a black background. The luminance of the disk was either $3.2,10$, or 32 $\mathrm{cd} / \mathrm{m}^{2}$ in 3 equal steps along a logarithmic scale. The effective luminance of the stimulus was calibrated with a Konica Minolta LS-100 Luminance Meter (Konica Minolta Holdings, Inc., Tokyo, Japan).

\section{Procedure}

Psychophysical and MEG experiment

We measured participants' perceived brightness by a magnitude estimation procedure during MEG recording in the magnetically shielded room. Participants' viewed the stimulus screen while lying supine in the MEG scanner. At the start of the experiment, the disk stimulus of $10 \mathrm{~cd} / \mathrm{m}^{2}$ was presented for 5 times as a standard stimulus. Participants then began the experimental trials. On each trial participants viewed 1 of the 3 disks of different luminance $\left(3.2,10\right.$, and $\left.32 \mathrm{~cd} / \mathrm{m}^{2}\right)$ presented for $500 \mathrm{~ms}$; after the disk had disappeared, the participant reported the perceived brightness of the disk aloud during inter-stimulus interval (ISI), given that the magnitude of the standard disk was 10 (Stevens, 1971). The inter-stimulus interval (ISI) was randomized between 1750 and 2250 ms. Participants were also required to maintain their fixation at the stimulus position throughout the experiment.
The stimuli were presented in a random order, with the constraint that each 1-back-and-current luminance pair was presented with an equal frequency within a block. The experimental session consisted of 5 blocks of 64 trials (320 trials in total); all 9 conditions (3 luminance values for 1-back trial $\times 3$ luminance values for current trial) were presented 7 times. The first trial was treated as a dummy trial. The entire session lasted approximately $30 \mathrm{~min}$.

\section{MEG Recordings and Data Analysis}

While participants observed the luminance disks, we recorded brain magnetic fields in a magnetically shielded room using a 160-channel wholehead MEG system (PQ1160C; Yokogawa, Tokyo, Japan). In order to co-register MEG channels with the participant's head, 5 position marker coils were attached to the participant's scalp (nasion and points immediately anterior to the ear canals) with a 3D digitizer (3Space Fastrak, Polhemus Inc., Colchester, VT, USA) before the MEG recording. At the beginning of the MEG recording, the position of the participant's head was determined with respect to the sensor array. The magnetic signals were digitized at $1000 \mathrm{~Hz}$ and low-pass filtered at $500 \mathrm{~Hz}$. Data was stored for off-line analysis.

Trials with strong artifacts (signal variation was larger than $3000 \mathrm{fT} / \mathrm{cm}$ ) were omitted from the analysis. We focused on the cortical response time-locked to the disk stimulus presentation. MEG responses were analyzed from $100 \mathrm{~ms}$ prior to, and $600 \mathrm{~ms}$ after, the disk stimulus onset. These data were averaged for each luminance condition across the trials. A low-pass filter was applied with the cutoff frequency at $50 \mathrm{~Hz}$. The peak amplitude and latency were determined from the time course of visual evoked MEG responses of 32 sensor outputs for each participant and stimulus condition. 


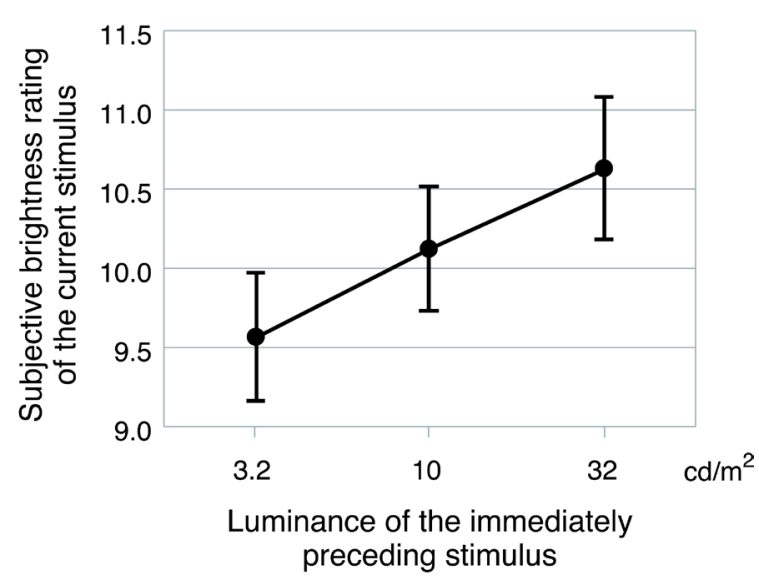

Figure 1. Subjective brightness rating as a function of luminance of immediately preceding stimulus.

Source: Own work.

\section{Results \& Discussion}

\section{Psychophysical Results}

To examine whether the brightness ratings of current trials were influenced by those of immediately preceding trials, we classify the data of each trial according to luminance of the 1-back stimulus. Figure 1 shows the averaged brightness rating in the current trial as a function of luminance of 1-back stimulus. The averaged perceived brightness of the current stimulus was 9.6, 10.1, and 10.6 for the immediately preceding stimulus of $3.2,10$, and $32 \mathrm{~cd} /$ $\mathrm{m}^{2}$ respectively $(\mathrm{SD}=1.2,1.18$, and 1.33 respectively). Clearly, the brightness rating was significantly higher when the luminance value of 1-back trial was larger, which was supported by a one-way ANOVA $(F(2,7)=14.14, p<0.0005)$ and following multiple comparisons (Ryan's method, $p<0.05$ ). These results showed that the magnitude judgments for perceived brightness showed assimilation towards the luminance of immediately preceding stimulus.

\section{MEG Results}

In this study, we recorded visual evoked magnetic responses from the following five regions consisting of 16 channels for each hemisphere: frontal, central, temporal, parietal, and occipital areas. To examine



Figure 2. MEG signals as a function of time from the stimulus onset of the current trial with luminance of the immediately preceding stimulus as a parameter.

Source: Own work.

whether the MEG responses to the current stimulus would show any relation to the stimulus on the immediately preceding trials, we classified the MEG responses on each trial according to luminance of 1-back stimulus; at first, we averaged the data for each 1-back-and-current luminance pair across the trials (9 conditions), then averaged these data depending on luminance of the 1-back stimulus (3 conditions). This was because some epochs with strong artifacts were omitted from the analysis, and thus the total number of trials for each condition was different.

There was no significant difference between each condition in the occipital regions, whose MEG signals are thought to be generated in areas around the primary visual cortex. On the other hand, we found a significant difference between 1-back luminance conditions in the left occipito-temporal regions. Fig. 2 shows the MEG responses in the left occipito-temporal regions as a function of time from the stimulus onset of the current trial with luminance of the immediately preceding stimulus as a parameter. The peak amplitude at around 200-220 ms differed significantly among the three conditions $(F(2,14)=8.37, p<0.005)$. A post hoc test indicated that the peak amplitude was larger for the 1 -back luminance of $3.2 \mathrm{~cd} / \mathrm{m}^{2}$ than for that of $10 \mathrm{~cd} / \mathrm{m}^{2}$ or the $32 \mathrm{~cd} / \mathrm{m}^{2}(p<0.05)$. These results showed that the neuromagnetic activation at a giv- 
TABLE 1.

Correlation Coefficients Between the Peak Amplitude and Perceived Brightness.

\begin{tabular}{cc}
\hline Subject & Correlation coefficient $(\mathrm{r})$ \\
\hline 1 & -0.98 \\
2 & -0.97 \\
3 & -0.93 \\
4 & -0.90 \\
5 & -0.87 \\
6 & -0.86 \\
7 & 0.12
\end{tabular}

en trial was weaker when the disk luminance was higher in the immediately prior trial.

To further investigate the nature of the MEG signal in the left occipito-temporal regions, we first measured the peak amplitude of the MEG signals as the highest amplitude from 150 to $250 \mathrm{~ms}$ after the onset of the disk stimulus. Then, we correlated the peak amplitude of MEG signals with the subjective brightness ratings. Table 1 shows the correlation coefficient $(r)$ for each participant. The response amplitude of the peak was negatively correlated with the subjective ratings of perceived brightness (Table 1). Across all participants except for two subjects, the correlation coefficients between the response amplitude of the peak versus subjective ratings of perceived brightness were significantly higher than zero (one-sample t-test, $t[7]=-3.0, p<0.05$ ).

\section{Discussion}

In this study, participants observed the disks with different luminance values and rated the perceived brightness of the disk. During the MEG session, we recorded MEG responses to those disks while the participants observed and evaluated them. The psychophysical data showed that perceived brightness increased as luminance of the immediately preceding stimulus increased. The MEG data revealed that the MEG signals from the left occipito-temporal area decreased as luminance of the immediately preceding stimulus increased. Moreover, this dependence of MEG responses on luminance of the immediately preceding stimulus was paralleled by the dependence of the perceived brightness. These findings suggest that the neuromagnetic activity in the left occipito-temporal regions may reflect the inter-trial modulation of luminance processing that are related with the subjective brightness.

We found that the neural activities in the left occipito-temporal regions depended on the temporal context; the item presented and judgment made on the previous trial. Regarding the neural activities depending on the spatial context, it is well-known that perceived brightness is affected by the luminance distribution in the surrounding visual field. For example, two circles of the same luminance appear to have different lightness if one is embedded in a dark surround and another in a bright surround. This phenomenon, which is called simultaneous lightness contrast, has been investigated extensively (e.g., Heinemann, 1955; Reid \& Shapley, 1989; Shevell, Holiday, \& Whittle, 1992). The simultaneous lightness contrast dramatically demonstrates the dissociation between the amount of light arriving at the retina and our perception. In single neuron recordings, it has already been demonstrated that the primary visual cortex exhibits a surround modulation that matches the contextual effects in human brightness perception. Recently, using stimuli varying in brightness contrast, some neuroimaging studies have also shown that there is a close correlation between fMRI or magnetoencephalography signals in primary visual cortex (V1) and the perceived contrast of stimuli (Haynes, Roth, Stadler, \& Heinze, 2003; Williams, Singh, \& Smith, 2003). However, the relationship of timing and location of cortical activity related to perceived brightness influenced by the temporal context, is still unclear. In the present study, taking advantage of the high spatio-temporal resolution of MEG, we showed that activation in the left occipito-temporal regions was dependent on the temporal context; luminance of the immediately preceding stimulus, as early as $200 \mathrm{~ms}$ after the onset of visual stimuli.

Although various factors have been reported as causes of the sequential effects, such as physical 
stimulus and response in preceding trials (for review see Stewart, Brown, \& Chater, 2005), the psychological interpretation of these effects are still under debate. Some researchers have suggested that the sequential effects are caused by the previous "stimulus" property (Garner, 1953; Holland \& Lockhead, 1968; Stewart et al., 2005), while others have suggested that both the "stimulus" and "response" properties in the previous trial cause the effects, but that the two factors contribute to the effect differently (Treisman 1985; Treisman \& Williams, 1984). In this study, the neural responses to the physical stimulus and response to them were partly confounded because the participants were required to observe and respond to all the stimuli presented. Clearly, further investigations are warranted to separate physical stimulus from response process. It would be interesting to clarify the sequential dependencies by systematically changing response requirements while using the same presentation sequence. It would also be informative to examine the temporal dynamics of temporal context-related responses in the left occipito-temporal areas.

Several recent studies have reported that the sequential effects are also observed in more complex, nonperceptual decisions (e.g., Beckstead, 2008; Matthews \& Stewart, 2009a; Vlaev \& Chater, 2007). For example, Matthews and Stewart (2009a) showed that the judgment of prices of merchandise (e.g., chairs, footwear) also susceptible to the sequential effect. Kondo et al. (2012) have recently investigated the sequential effect in face-attractiveness judgment and found that the attractive ratings are biased toward those on the preceding trials. Thus, further investigations are needed to clarify the relationship between the neural activities and the various types of sequential effects.

In conclusion, this study showed that the neuromagnetic activation in the left occipito-temporal regions depends on luminance of the immediately preceding stimulus that are related to the subjective perception of brightness as early as 200-220 ms after the onset of visual stimuli.

\section{References}

Beckstead, J. W., (2008). Modeling sequential context effects in judgment analysis: A time series approach. Judgment and Decision Making, 3, 570-584.

Brainard, D. H. (1997). The Psychophysics Toolbox. Spatial Vision, 10, 433-436.

DeCarlo, L. T., \& Cross, D. V. (1990). Sequential effects in magnitude scaling: Models and theory. Journal of Experimental Psychology: General, 119, 375-396.

Eriksen, C. W., \& Hake, H. W. (1955). Absolute judgments as a function of stimulus range and the number of stimulus and response categories. Journal of Experimental Psychology, 49, 323-332.

Garner, W. R. (1953). An informational analysis of absolute judgments of loudness. Journal of Experimental Psychology, 46, 373-380.

Haynes, J. D., Roth, G., Stadler, M., \& Heinze, H. J. (2003). Neuromagnetic correlates of perceived contrast in primary visual cortex. The Journal of Neurophysiology, 89, 2655-2666.

Haynes, J., Lotto, R. B., \& Rees, G. (2004). Responses of human visual cortex to uniform surfaces. Proceedings of the National Academy of Sciences of the United States of America, 101, 4286-4291.

Heinemann, E. G. (1955). Simultaneous brightness induction as a function of inducing-and test-field luminances. Journal of Experimental Psychology, 50, 89-96.

Holland, M. K., \& Lockhead, G. R. (1968). Sequential effects in absolute judgments of loudness. Perception Ef Psychophysics, 3, 409-414.

Jesteadt, W., Luce, R. D., \& Green, D. M. (1977). Sequential effects of the judgments of loudness. Journal of Experimental Psychology: Human Perception and Performance, 3, 92-104.

Kondo, A., Tsubomi, H., \& Watanabe, K. (2010). Neuromagnetic correlates of perceived brightness in human visual cortex. Psychologia, 53 (4), 267-275.

Kondo, A., Takahashi, K., \& Watanabe, K. (2012). Sequential Effects in Face-attractiveness Judgment. Perception, 41 (1), 43-49.

Luce, R. D., \& Green, D. M. (1974). The response ratio hypothesis for magnitude estimation, Journal of Mathematical Psychology, 11, 1-14. 
Matthews, W. J., \& Stewart, N. (2009a). Psychophysics and the Judgment of Price: Judging Complex Objects on a Non-physical Dimension Elicits Sequential Effects Like Those in Perceptual Tasks. Judgment and Decision Making, 4, 64-81.

Matthews, W. J., \& Stewart, N. (2009b). The effect of inter-stimulus interval on sequential effects in absolute identification. Quarterly Journal of Experimental Psychology, 62(10), 2014-2029.

Osaka, N., \& Yamamoto, M. (1978). VEP latency and RT as power functions of luminance in the peripheral visual field. Electroencephalography $\mathcal{E}$ clinical neurophysiology, 44, 785-788.

Pelli, D. G. (1997). The VideoToolbox software for visual psychophysics: Transforming numbers into movies. Spatial Vision, 10, 437-442.

Reid, R. C. \& Shapley, R. M. (1989). Non-local effects in the perception of brightness: psychophysics and neurophysiology. In Kulikowski, J. J., Dickinson, C. M. \& Murray, I. J. (Eds), Seeing contour and colour, (pp. 324-333). Oxford: Pergamon Press.

Shevell, S. K., Holiday, I. \& Whittle, P. (1992). Two separate neural mechanisms of brightness induction. Vision Research, 3212, 2331-2340.

Stevens, S. S. (1971). Issues in psychophysical measurement. Psychological Review, 78, 426-450.
Stewart, N., Brown, G. D. A., \& Chater, N. (2005). Absolute identification by relative judgment. Psychological Review, 112, 881-911.

Treisman, M., \& Williams, T. C. (1984). A theory of criterion setting with an application to sequential dependencies. Psychological Review, 91, 68-111.

Treisman, (1985). The magical number seven and some other features of category scaling: Properties for a model of absolute judgment. Journal of Mathematical Psychology, 29, 175-230.

Vlaev, I., \& Chater, N. (2007). Context effects in games: Local versus global sequential effects on choice in the prisoner's dilemma game. Judgment and Decision Making, 2, 380-389.

Ward, L. M., \& Lockhead, G. R. (1970). Sequential effect and memory in category judgment. Journal of Experimental Psychology, 84, 27-34.

Ward, L. M. (1982). Mixed-modality psychophysical scaling: Sequential dependencies and other properties. Perception $\mathcal{E}$ Psychophysics, 31, 53-62.

Wicke, J. D., Donchin, E. \& Lindsley D. B. (1964). Visual evoked potentials as a function of flash luminance and duration. Science, 146, 83-85.

Williams, A. L., Singh, K. D., \& Smith, A. T. (2003). Surround modulation measured with functional MRI in the human visual cortex. The Journal of Neurophysiology, 89, 525-533. 
